\title{
Life assessment of marine ethylene propylene rubber power cables based on hardness retention rate
}

\author{
Xiaokai Meng, Zhiqiang Wang, Guofeng Li \\ Faculty of Electronic information and Electrical Engineering \\ Dalian University of Technology, Dalian, China \\ e-mail:mengxiaokai870618@163.com
}

(Received: 24.08.2016, revised: 20.02.2017)

\begin{abstract}
The lifetime of ethylene propylene rubber (EPR) insulated cables will decrease because of complex aging processes. From the safety perspective, insulation condition assessment of the cable is essential to maintain an efficient and reliable operation. As a nondestructive and online evaluation method, a hardness retention rate was used to estimate the lifetime of cable. First, accelerated thermal aging tests in the laboratory were performed to measure the elongation at break retention rate $(\mathrm{EAB} \%)$ and a hardness retention rate at different temperatures. Second, the aging values were processed by the Arrhenius equation and time temperature superposition to assess aging lifetime of insulation at different temperatures and end levels. As the insulation condition assessment of the cable by hardness retention test has no approved standard, the $\mathrm{EAB} \%$ data were correlated with hardness retention to provide an evaluation basis. The results show that when $\mathrm{EAB} \%$ picks out the time corresponding to a certain amount of $50 \%$ degradation, $10 \%$ of hardness retention was chosen as the termination index.
\end{abstract}

Key words: ethylene propylene rubber (EPR), nondestructive, hardness retention rate, elongation at break retention rate (EAB \%), termination index

\section{Introduction}

There are many cables that perform safety-related roles in marine and should implement condition monitoring during the operation period to assess the remaining qualified life and extend the qualified life. Under the normal operation condition, cables may be exposed to high heat, humidity, thermal and mechanical shock, which can cause them to lose their desired characteristics earlier than expected and accelerate their aging. While faults can occur in any portion of a cable, there is a need to develop advanced methods for nondestructive evaluation of cable insulation that is universally applicable [1].

In-situ, main test technique for cable maintenance is visual and tactile inspection, which identifies cracks, visible contamination and discoloration of the cables [2]. In an industrial 
test, the key indicators of the cable's condition are its mechanical, chemical and electrical properties of age-related degradation [3].

Commonly used analytical techniques for mechanical property changes include elongation at break (EAB), indenter modulus (IM), dynamic mechanical analysis (DMA) and ultrasonic measurements (UM) [4]. Chemical property changes include differential scanning calorimeter (DSC), thermo-gravimetric analysis (TGA) and Fourier transform infrared spectrometer (FTIR). Electrical property changes include time-frequency domain reflectometry (TDR and FDR), insulation resistance (IR), partial discharge (PD) and tan delta.

Table 1 summarizes the pros and cons of the various inspection methods that are considered viable for detecting flaws and aging in cables. As can be seen in Table 1, DMA, UM, DSC, TGA, FTIR, TDR/FDR and Tan-delta need expensive testing equipment and trained personnel [5]. IR needs to disconnect the cables to install instrumentation. PD is good for determining voids or defects in insulation of medium voltage cables, but not suitable for the cable described in this paper. The EAB has been widely accepted as an industry standard to predict remaining lifetime, but it needs a large amount of samples, and an experiment time is longer in other methods. Moreover, all methods except IM, TDR/FDR and Tan-delta profiling are destructive, while EAB and IM were the most common tests performed.

Table 1. Comparison of cable inspection methods

\begin{tabular}{|c|c|c|c|c|c|c|c|}
\hline Method & Sensitivity & $\begin{array}{c}\text { Wide } \\
\text { applicability }\end{array}$ & $\begin{array}{c}\text { Amount } \\
\text { of sample }\end{array}$ & Destructive & $\begin{array}{l}\text { Detection } \\
\text { range }\end{array}$ & Cost & On line \\
\hline \multicolumn{8}{|c|}{ mechanical } \\
\hline $\mathrm{EAB}$ & high & yes & large & yes & part & low & no \\
\hline IM & high & no & none & no & part & low & yes \\
\hline DMA & high & no & small & yes & part & low & no \\
\hline $\mathrm{UM}$ & high & no & small & no & part & high & no \\
\hline \multicolumn{8}{|c|}{ chemical } \\
\hline DSC & high & yes & small & yes & part & high & no \\
\hline TGA & high & yes & small & yes & part & high & no \\
\hline FTIR & high & no & small & yes & part & high & no \\
\hline \multicolumn{8}{|c|}{ electrical } \\
\hline T/FDR & high & yes & none & no & whole & high & no \\
\hline IR & low & yes & none & no & whole & low & yes \\
\hline Tan & high & yes & none & no & whole & high & yes \\
\hline $\mathrm{PD}$ & low & no & none & no & part & high & yes \\
\hline
\end{tabular}

We focused on the IM, which can measure the hardness retention rate of the cable described in this article [6]. This method is selected because it is nondestructive and needs short testing time and small sized equipment. Because the insulation condition assessment of the cable by hardness retention rate test has no approved standard [7], the goal of the research presented in this paper is to correlate hardness retention measurement with $\mathrm{EAB} \%$ data 
through the lab test to provide an assessment of a cable's current condition as well as its remaining useful life (RUL).

\section{Experimental methods}

Fig. 1 shows the structure of the $0.6 / 1 \mathrm{kV}$ EPR cable and the cross sectional area of the conductor is $120 \mathrm{~mm}^{2}$. The cable consists of: the copper conductor, EPR insulation and outer sheath. The experiment specimens were prepared by removing the sheath and the central conductor to leave only the insulation layer.

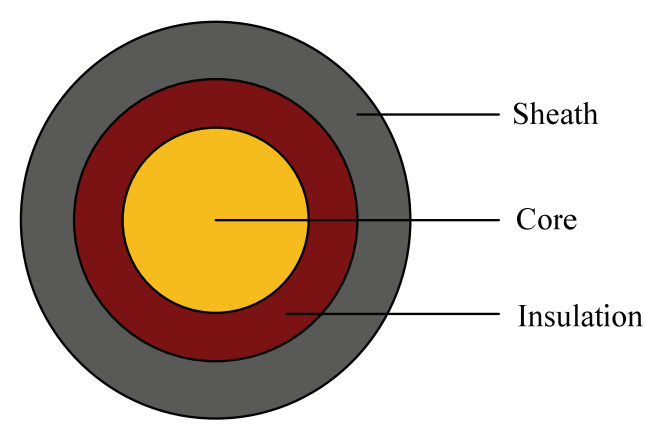

Fig. 1. The cross section of EPR cable

In this paper, the insulation layer was selected as the raw materials and according to the IEC 60811-1-1:2001, IDT, the shape and dimension of dumb-bell specimens were shown in Fig. 2. A manual punching machine was used to make dumb-bell specimens and a sample thickness of $2 \mathrm{~mm}$ and difference less than $0.1 \mathrm{~mm}$ was chosen as the standard specimens.

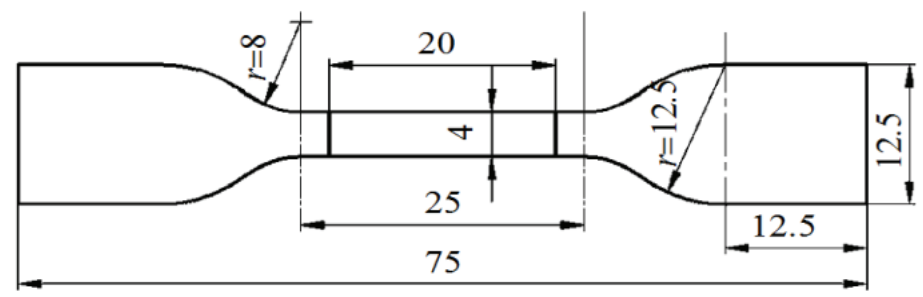

Fig. 2. Dimension of dumb-bell specimen (mm)

\subsection{Accelerated thermal aging}

Electric ovens with air circulating fans were used to accelerate aging of specimens. According to specification of American power stations and IEC 60216, the accelerated thermal aging temperatures of $120^{\circ} \mathrm{C}, 135^{\circ} \mathrm{C}, 150^{\circ} \mathrm{C}$ and $165^{\circ} \mathrm{C}$ were selected. There were five standard dumb-bell specimens aged in different sampling periods of each ageing temperature. Thermal aging temperatures and sampling periods were shown in Table 2. 
Table 2. Thermal aging temperatures and sampling periods

\begin{tabular}{c|c|c|c|c|c|c|c|c}
\hline Temperature & \multicolumn{7}{|c}{ Periods/h } \\
\hline $120^{\circ} \mathrm{C}$ & 120 & 192 & 264 & 456 & 648 & 1108 & 1440 & 2088 \\
\hline $135^{\circ} \mathrm{C}$ & 96 & 192 & 240 & 360 & 456 & 648 & 1108 & 1272 \\
\hline $150^{\circ} \mathrm{C}$ & 48 & 96 & 144 & 192 & 240 & 288 & 312 & 324 \\
\hline $165^{\circ} \mathrm{C}$ & 24 & 36 & 48 & 60 & 72 & 84 & 96 & 108 \\
\hline
\end{tabular}

\subsection{Elongation at break measurement}

The specimens were air cooled for $16 \mathrm{~h}$ after finishing the accelerated aging. The JDL-1000 tensile machine was used to measure the elongation of the cable under different aging conditions and the speed of elongation was $50 \mathrm{~mm} / \mathrm{min}$ and at $23 \pm 2{ }^{\circ} \mathrm{C}, 50 \% \mathrm{RH}$. There were five standard dumbbell samples at each experimental temperature. One of the most common methods for EAB\% was to use the Arrhenius Equation (1), where $t_{1}$ is the estimated age, $t_{2}$ is the time the specimen was aged, $T_{1}$ is the service temperature, $T_{2}$ is the aging temperature, $E_{a}$ is the activation energy, and $R$ is the Boltzmann constant.

$$
t_{1}=t_{2} e^{\left[\left(E_{a} / R\right)\left(1 / T_{1}-1 / T_{2}\right)\right]}
$$

\subsection{Hardness retention rate}

Hardness testing is a nondestructive aging evaluation method, which measures the hardness retention of a cable by pressing a cable surface with a steel probe in the vertical direction.

According to the standard of GB/T531.1-2008, ISO 7619-1:2004 and the thickness of the specimens, the Shore AM durometer was used to determine the hardness of the insulation. There were five points tested were made for each aged cable specimen. The lowest and highest values were excluded and the remaining values were used in the statistical evaluation. According to the calculation method of property variation percent during aging in $\mathrm{GB} / \mathrm{T}$ $3512-2014$, the hardness retention was proposed in this paper and the equation was described as e.g. (2):

$$
p=\frac{100-X}{100} \times 100 \%
$$

where: $p$ is the hardness retention rate; $X$ is the hardness value after aging.

\subsection{Time-temperature superposition}

Time-temperature superposition has been used for long-term structural durability design with short-term accelerating tests at elevated temperatures [8]. Many previous work [9] had shown that the time-temperature shifting was applicable to the life estimation of insulation materials. Correspondence between the time and the temperature can be achieved by timetemperature shifting with suitable shift factors $\alpha_{T i}$, it could be described as e.g. (3): 


$$
\alpha_{T i}=\frac{t_{\mathrm{ref} i}}{t_{i}},
$$

where: $t_{\text {ref } i}$ is the time of reference temperature $T_{\text {ref }}, t_{i}$ is the original time before shifted at $T$.

The shift factors can be correlated with the temperature by the Arrhenius Eq. as e.g. (4):

$$
\ln \alpha_{T i}=\frac{E_{a}}{R}\left(\frac{1}{T_{\text {ref }}}-\frac{1}{T}\right) .
$$

For calculation the reliability of the time-temperature shift factors at each temperature, an optimal calculation method was proposed as e.g. (5):

$$
R^{2}=\frac{S_{x y}^{2}}{S_{x x} S_{y y}},
$$

where:

$$
\begin{gathered}
S_{x x}=\sum_{i=1}^{n} \sum_{j=1}^{n_{i}}\left(\alpha_{T i} t_{i j}\right)^{2}-\frac{1}{\sum_{i=1}^{m} n_{i}}\left(\sum_{i=1}^{n} \sum_{j=1}^{n_{i}} \alpha_{T i} t_{i j}\right)^{2}, \\
S_{y y}=\sum_{i=1}^{n} \sum_{j=1}^{n_{i}}\left(P_{i j}\right)^{2}-\frac{1}{\sum_{i=1}^{m} n_{i}}\left(\sum_{i=1}^{n} \sum_{j=1}^{n_{i}} P_{i j}\right)^{2}, \\
S_{x y}=\sum_{i=1}^{n} \sum_{j=1}^{n_{i}} \alpha_{T i} t_{i j} P_{i j}-\frac{1}{\sum_{i=1}^{m} n_{i}}\left(\sum_{i=1}^{n} \sum_{j=1}^{n_{i}} \alpha_{T i} t_{i j}\right)\left(\sum_{i=1}^{n} \sum_{j=1}^{n_{i}} P_{i j}\right),
\end{gathered}
$$

where: $\alpha_{T i}=1, \alpha_{T i}>1(i=2, \ldots, m=4), i$ presents the sequence numbers of each temperature, $j=1, \ldots . n_{i}=8$ are the sequence numbers of $i, p_{i j}$ is the insulation property variation percent, $t_{i j}$ is the aging time.

\section{Results and discussion}

The cable insulation was thermally aged at $120^{\circ} \mathrm{C}, 135^{\circ} \mathrm{C}, 150^{\circ} \mathrm{C}$ and $165^{\circ} \mathrm{C}$, Table 3 showed the average value of $\mathrm{EAB} \%$ and the hardness retention rate $(P)$ for different thermal aging time. The $\mathrm{EAB} \%$ and $P$ were decreased with the increase of aging time.

According to time-temperature superposition theory, the $\mathrm{EAB} \%$ and $P$ values of thermal aging temperature of $120^{\circ} \mathrm{C}$ were selected as the reference temperature, then shifting data at 
each higher temperature of $135^{\circ} \mathrm{C}, 150^{\circ} \mathrm{C}$ and $165^{\circ} \mathrm{C}$ horizontally by the constant multiplicative factor that gives the best overall superposition used the optimal calculation method with the reference curve $\left(\alpha_{T}=1\right.$ for the reference temperature).

Table 3. The experimental data of $\mathrm{EAB} \%$ and hardness retention rate testing

\begin{tabular}{|c|c|c|c|c|c|c|c|}
\hline Temperature $/{ }^{\circ} \mathrm{C}$ & Time/h & EAB\% & $\mathbf{P}(\%)$ & Temperature $/{ }^{\circ} \mathrm{C}$ & Time/h & EAB\% & $\mathbf{P}(\%)$ \\
\hline \multirow{8}{*}{$120^{\circ} \mathrm{C}$} & 120 & 97.7 & 31.4 & \multirow{8}{*}{$135^{\circ} \mathrm{C}$} & 96 & 94.8 & 30 \\
\hline & 192 & 94.3 & 30.8 & & 192 & 90 & 28.8 \\
\hline & 264 & 92.5 & 30.2 & & 240 & 88.1 & 27.7 \\
\hline & 456 & 85.8 & 27.4 & & 360 & 84.4 & 26.5 \\
\hline & 648 & 78.8 & 25 & & 456 & 78.8 & 25.8 \\
\hline & 1108 & 67.1 & 19 & & 648 & 70 & 23 \\
\hline & 1440 & 56.1 & 16 & & 1108 & 48 & 14 \\
\hline & 2088 & 15.2 & 7 & & 1272 & 22.2 & 9 \\
\hline \multirow{8}{*}{$150^{\circ} \mathrm{C}$} & 48 & 90.1 & 29 & \multirow{8}{*}{$165^{\circ} \mathrm{C}$} & 24 & 88.3 & 28.6 \\
\hline & 96 & 83.4 & 28.2 & & 36 & 82.6 & 27.8 \\
\hline & 144 & 79.6 & 26.4 & & 48 & 76.8 & 27 \\
\hline & 192 & 70.6 & 24 & & 60 & 70.3 & 25 \\
\hline & 240 & 60.3 & 20 & & 72 & 64.8 & 21 \\
\hline & 288 & 45 & 14 & & 84 & 60.8 & 17 \\
\hline & 312 & 22.9 & 11 & & 96 & 54 & 14 \\
\hline & 324 & 18.7 & 8 & & 108 & 27.3 & 10 \\
\hline
\end{tabular}

As shown in Fig. 3 and Fig. 4 , the shift factors of $\mathrm{EAB} \%$ and $P$ were $(18,6.4,1.6,1)$ and $(17,5.8,1.6,1)$, respectively. It is clear that the EAB\% and $P$ change curves at different temperatures have the same shape and show an excellent superposition.

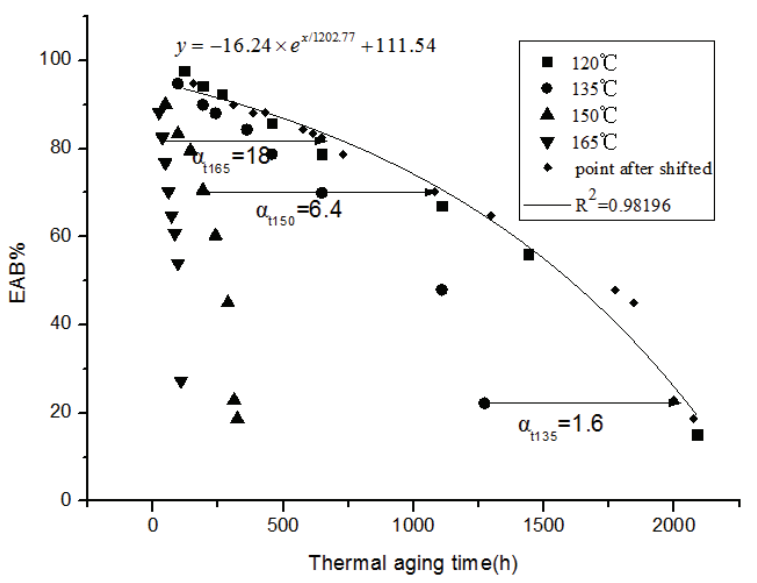

Fig. 3. The fitting curve of $\mathrm{EAB} \%$ 


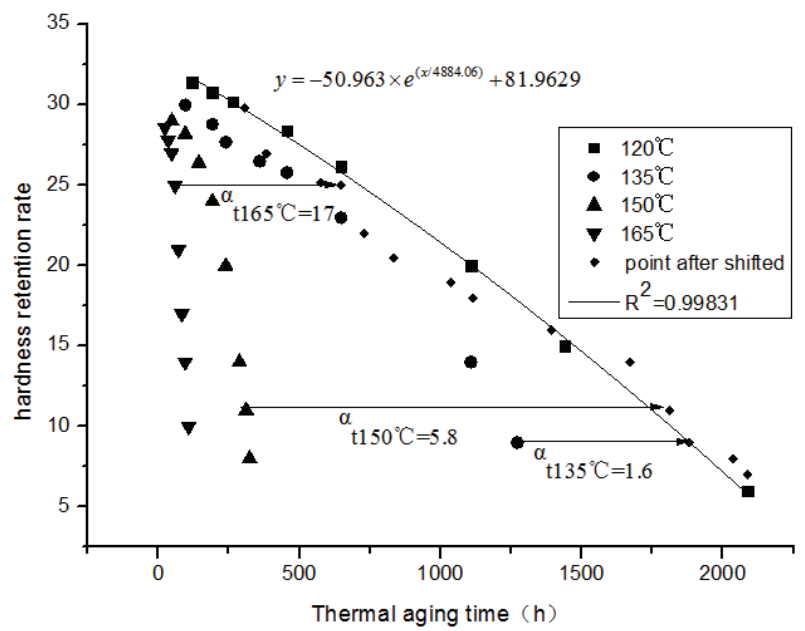

Fig. 4. The fitting curve of hardness retention rate

The fitting curve equations were described as e.g. (9):

$$
\left\{\begin{array}{l}
\mathrm{EAB} \%=-16.24 \times e^{t / 1202.77}+111.54 \\
P=-50.963 \times e^{t / 4884.06}+81.9629
\end{array},\right.
$$

where: $t$ is the aging time at $120^{\circ} \mathrm{C}, P$ is the hardness retention rate; $\mathrm{EAB} \%$ presents elongation at break retention rate.

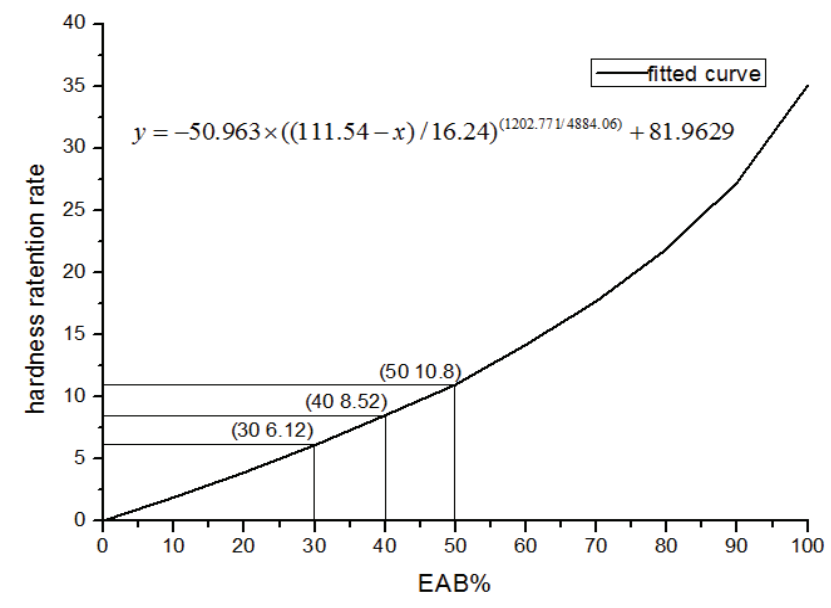

Fig. 5. The relation of $\mathrm{EAB} \%$ and hardness retention rate

Once the shift factors are determined, they can be tested with Arrhenius Equation 4, the slope of the $\ln \left(\alpha_{\mathrm{T}}\right)$ versus inverse absolute temperature yields a linear curve with the slope representing the activation energy, as shown in Fig. 6. 


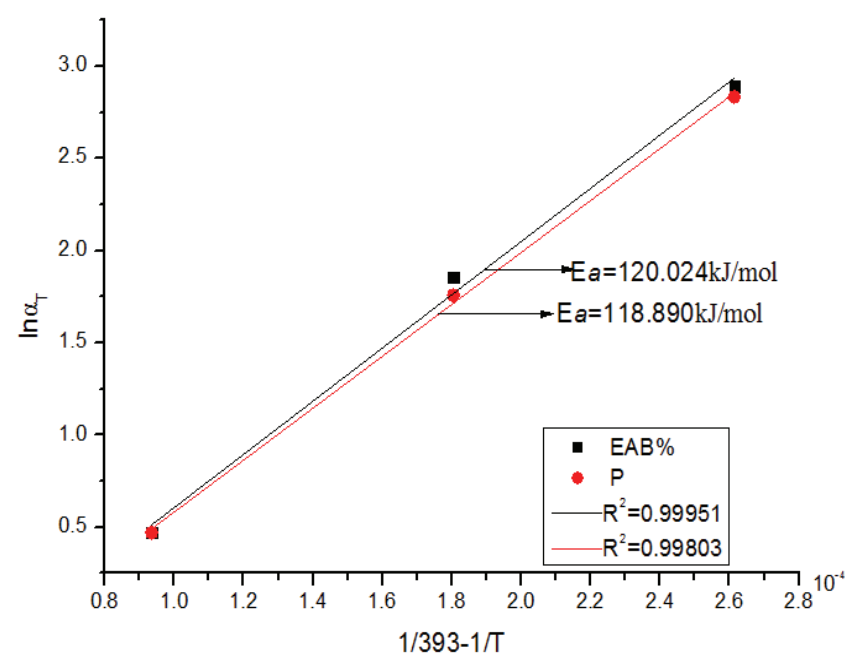

Fig. 6. The Arrhenius plot of the shifting factors at a reference temperature of $120^{\circ} \mathrm{C}$

The activation energy represents the minimum energy needed for the aging reactions to occur. By obtaining the activation energy from the accelerated aging tests and assuming the aging reaction remains the same at lower temperatures, the lifetime can be predicted for the low-temperature, long-term aging conditions. The activation energy values obtained from the EAB\% and the $P$ were $120.024 \mathrm{~kJ} / \mathrm{mol}$ and $118.890 \mathrm{~kJ} / \mathrm{mol}$, respectively.

\section{Life prediction and correlation}

The traditional Arrhenius analysis of EAB\% usually picks out the time corresponding to a certain amount of $30 \%-50 \%$ degradation, but an indent test has no approved standard. In order to provide a standard to determine the lifetime through the indent test, this paper correlate hardness retention rate with $\mathrm{EAB} \%$ data to provide the assessment of a cable's current condition as well as its usefulness in life.

According to Equation 4 and the activation energy, the lifetime of cable insulation under different temperatures as well as end levels as shown in Table 4. It can be seen that the errors between $\mathrm{EAB} \%$ and the hardness retention rate at different temperatures and end levels were very small. When $\mathrm{EAB} \%$ picked out the time corresponding to a certain amount of $50 \%, 40 \%$ and $30 \%$ degradation, the termination index of hardness retention was between $10.8 \%, 8.52 \%$ and $6.12 \%$. The histograms shown here demonstrate that when the working temperatures were $70^{\circ} \mathrm{C}, 75^{\circ} \mathrm{C}, 80^{\circ} \mathrm{C}$ and $85^{\circ} \mathrm{C}$, the maximum differences were $2.3 \mathrm{a}, 1.1 \mathrm{a}, 0.5 \mathrm{a}$ and $0.2 \mathrm{a}$, so it was proved that the nondestructive evaluation method based on a hardness retention rate can correctly predict the durability of cable under different condition. It can also be seen that only the temperature effect was considered in the calculation in this paper and a certain margin of error was lift, so only $10 \%$ of the hardness retention rate was chosen as the termination index. 
Table 4. The aging lifetime (a) of cable under different temperatures and end levels

\begin{tabular}{l|c|c|c|c}
\hline $\mathbf{T}$ & $\mathbf{7 0}^{\circ} \mathbf{C}$ & $\mathbf{7 5}^{\circ} \mathbf{C}$ & $\mathbf{8 0}^{\circ} \mathbf{C}$ & $\mathbf{8 5}^{\circ} \mathbf{C}$ \\
\hline EAB\% $=50 \%$ & 38.7 & 21.1 & 11.7 & 6.6 \\
\hline $\mathrm{P}=11 \%$ & 37.1 & 20.4 & 11.4 & 6.5 \\
\hline $\mathrm{EAB} \%=40 \%$ & 43.1 & 23.5 & 13.1 & 7.4 \\
\hline $\mathrm{P}=8.52 \%$ & 41.0 & 22.5 & 12.6 & 7.2 \\
\hline $\mathrm{EAB} \%=30 \%$ & 46.9 & 25.6 & 14.2 & 8.0 \\
\hline $\mathrm{P}=6.12 \%$ & 44.6 & 24.5 & 13.7 & 7.8 \\
\hline
\end{tabular}

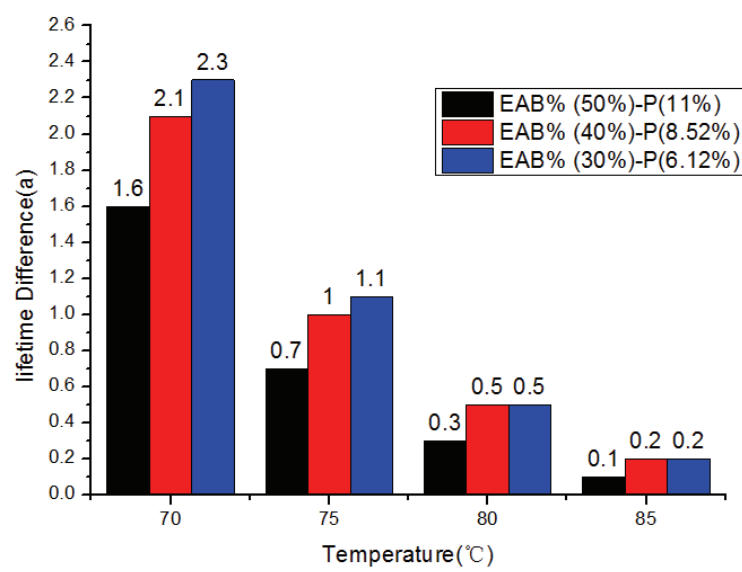

Fig. 7. The difference between $\mathrm{EAB} \%$ and hardness retention rate

\section{Conclusions}

The insulation of EPR cable was subjected to age at $120^{\circ} \mathrm{C}, 135^{\circ} \mathrm{C}, 150^{\circ} \mathrm{C}$, and $165^{\circ} \mathrm{C}$. The following conclusions can be drawn:

1) The elongation at break retention rate and hardness retention rate of specimens were measured, the data at different aged time were successfully superimposed by horizontal shifting along the logarithmic time axis according to the Arrhenius equation.

2) Based on $\mathrm{EAB} \%$ picks out the time corresponding to a certain amount of $50 \%$ degradation, the termination index of hardness retention was $10.8 \%$. Taking the other factors into consideration, $10 \%$ of hardness retention rate was chosen as the termination index.

3) The detection method of hardness retention rate proposed in this paper is a nondestructive procedure. One just needs to know the hardness retention rate value of cable obtained in the process of testing, and then the method is easy to implement.

\section{Acknowledgements}

The authors would like to thank for the support from the international science \&technology cooperation program of China, the doctoral start fund of Liaoning Province, and the fundamental research funds for the central universities. 


\section{References}

[1] Shumaker B.D., Campbell C.J., Sexton C.D. et al., Cable condition monitoring for nuclear power plants, Future of Instrumentation International Workshop (FIIW), Gatlinburg, pp. 1-4 (2012).

[2] Hashemian H.M., Mcconkey B., Harmon G. et al., Methods for testing nuclear power plant cables, IEEE Instrumentation \& Measurement Magazine, vol. 16, no. 7, pp. 31-36 (2013).

[3] Kaynak C., Ibibikcan E., Contribution of nanoclays to the flame retardancy of polyethylene-based cable insulation materials with aluminum hydroxide and zinc borate, Journal of Fire Sciences, vol. 32, no. 2, pp. 121-144 (2014).

[4] Simmons K.L., Fifield L.S., Westman M.P., Ramuhalli P., Pardini A.F., Tedeschi J.R., Jones A.M., Determining Remaining Useful Life of Aging Cables in Nuclear Power Plants-Interim Study FY13, Pacific Northwest Nat. Lab., Richland, WA, USA, Tech. Rep. PNNL-22812, pp. 1-5 (2013).

[5] Li Z., Moon K.S., Yao Y. et al., Carbon nanotube/polymer Nano composites: Sensing the thermal aging conditions of electrical insulation components, Carbon, vol. 65, pp. $71-79$ (2013).

[6] Shumaker B.D., McCarter D.E., Hashemian H.M. et al., Frequency domain reflectometry for remaining useful life estimation of instrumentation and control cables, Proceedings of the Institution of Mechanical Engineers, Part O: Journal of Risk and Reliability, vol. 229, no. 4, pp. 301-309 (2015).

[7] Kim J.S., Study of relational equation between indent for cable aging evaluation, Transactions of the Korean Nuclear Society Spring Meeting, Korea, pp. 1-2 (2007).

[8] Umberger P.D., Case S.W., Cook F.P., Time-temperature superposition and high rate response of thermoplastic composites and constituents, Time Dependent Constitutive Behavior and Fracture/ Failure Processes, vol. 3, pp. 139-146 (2011).

[9] Celina M., Gillen K.T., Assink R.A., Accelerated aging and lifetime prediction: review of nonArrhenius behavior due to two competing processes, Polymer Degradation and Stability, vol. 90, no. 3, pp. 395-404(2005). 